\section{Kovalenko $\mathbf{Y}$., Klymenko A., Tokarchuk V., Sviderskyi V.}

\title{
EFFECT OF SULFATE ION ENVIRONMENT ON PHYSICAL AND MECHANICAL DURABILITY OF CEMENT PRODUCTS MODIFIED BY CELIULOSE ETHERS
}

The object of research is organic additives of methyl hydroxyethyl cellulose of medium and high viscosity, namely, their nature of the effect on the physical and mechanical durability under the destructive influence of various sulfate-ionic media. The need to study the nature of the effect of this additive on resistance to an aggressive environment is also associated mainly with the expansion of the types of building mixtures to create competitive products without losing product quality and to improve the mechanical and rheological properties.

In the course of the study, cellulose ethers of medium (17000-23000 mPa.s) and high (20000-30000 mPa.s) viscosity were used. Additives were added to the cement in the amount of 0.25, 0.5 and 0.75 wt. \%. It was found that the introduction of cellulose ether into cement leads to an increase in the normal density of the dough and an extension of the setting time of solutions, in turn, affects the process of strength gain of the latter, in comparison with control samples without additives. With the introduction of the additive, the rate of water separation of the mixtures also significantly decreases, indicating the water-retention capacity of the additive. For the concentration of additives in the amount of $0.25 \mathrm{wt}$. \%. This decrease is 2 times less than for control samples. For a concentration of 0.5-0.75 wt. \% water loss is reduced by 3 times compared to samples without additive. Significant changes also occur during the early strength gain of the samples with an increase in the additive concentration. The destructive effect of an aggressive sulfate medium was determined by the change in compressive strength. With prolonged exposure to an aggressive environment on control and test samples, it is noted that the introduction of this additive of organic origin negatively affects the strength characteristics of cement mixtures with cellulose ethers with an increase in the additive content. The above results indicate the advisability of using cellulose ethers of medium viscosity in dry building mixtures as such, which will provide the necessary storage time for the fluidity of the solution and sufficient strength of the final material.

Keywords: dry building mixtures, methyl hydroxyethyl cellulose, normal density, setting time, water separation, aggressive environment.

Received date: 03.08 .2020

Accepted date: 24.09 .2020

Published date: 31.12 .2020
Copyright (C) 2020, Kovalenko Y., Klymenko A., Tokarchuk V., Sviderskyi V. This is an open access article under the CC BY license (http://creativecommons.org/licenses/by/4.0)

\section{Introduction}

The development trend of the market of dry building mixtures and their varieties is increasing every year, as well as the methods of their application [1,2]. The popularity of these materials is associated with a certain number of advantages that ensure an increase in labor productivity, a decrease in the number of operations for preparing mixtures for use, an increase in the quality of work, etc. Dry building mixtures include multicomponent mixtures that necessarily include a binder, filler (filler) and modifying additives [3]. Each of these materials plays a role.

Depending on the type of additives, the final mixture is provided with a number of properties, including increased strength and durability. However, there is also a negative impact on these indicators. In humid environments, soil, groundwater and seawater, the impact on the integrity of cement-based structures occurs through the destructive effect of sulfate ions. In the hardened cement, the component of reaction with sulfate ions is Alite, which in the presence of calcium hydroxide forms ettringite and gypsum, which leads to the formation of compounds that lead to the expansion and destruction of the final product [4-6].

Experiments on the effect of aggressive media on cement products [5-7] led, in turn, to the creation of specialized types of cements, the mineralogical composition of which is mainly focused on resisting the aggressive effects of sulfate without losing the strength characteristics of structures. However, during the outstanding period there were changes not only in the chemical and mineralogical composition of cement, but also in most products based on them [8-10]. This is especially true for dry building mixtures, the use of which in our time has spread beyond their usual areas of application in such a way that the question of their resistance to aggressive media arises next to the question of their durability [11, 12].

\section{The object of research and its technological audit}

The object of research is organic additives of methyl hydroxyethyl cellulose of medium and high viscosity, namely, 
their nature of the effect on the physical and mechanical durability under the destructive action of various sulfateionic media.

The need to study the nature of the effect of this additive on resistance to aggressive media is also associated mainly with the expansion of the range of building mixtures to create competitive products without losing product quality and to improve the mechanical and rheological properties. Most building mixtures are used as repair or plastering mortars in environments where there is a destructive effect of aggressive components, such as environments containing sulfate ions:

- groundwater;

- sea water;

- wastewater;

- premises for chemical production;

- industrial zones;

- other environments where the influence of sulfate compounds is present.

That is why the main task of the study is to study the nature of the effect of cellulose ether additives on the physicomechanical and rheological properties and the relationship under the destructive action of media containing sulfate ions.

Thus, this study is of particular importance in connection with the possibility of using the obtained data to improve the production formulations of building mixtures and to address issues related to improving the characteristics of strength and durability of products.

\section{The aim and objectives of research}

The aim of research is to establish the influence of the characteristics of methyl hydroxyethyl cellulose on the strength of cement, which is the main binding component of most dry building mixtures. The results obtained will allow developing formulations of mixtures with the best indicators of durability and strength.

To achieve this aim, it is necessary to complete the following objectives:

1. To study the nature of the influence of cellulose ether additives with different viscosity on normal density, setting time, water separation of the cement mixture and water absorption of cement stone.

2. To investigate the influence of the viscosity of the additives on the strength gain for 28 days in an environment without the influence of sulfate ions.

3. To determine the nature of the change in strength during prolonged exposure to an aggressive environment after strength gain in an environment with no influence of sulfate ions.

\section{Research of existing solutions of the problem}

In [13], special attention was paid to the physicochemical and physico-mechanical properties of the material under the influence of additives of cellulose esters (methyl hydroxyethyl cellulose). It should be noted that despite the increased efficiency of working hours of mixtures with additives, the content of cellulose esters has a dramatic effect on the resistance of cement products to the influence of sulfate ionic medium depending on the concentration of the additive and the type of aggres- sive environment. The obtained results are confirmed in other works [14], which describes the ability of cellulose esters to slow down the hydration process and prevent the absorption of water present in the solution into the porous surface of the base, while preventing evaporation. This process increases the working time of the mixture and its adhesive ability. However, the studied effect of the viscosity of the additives on the set of strength [13] confirms that the higher the viscosity of cellulose ether, the less it must be added to the dry mixture. However, the problem that the density of mortars increases significantly at high viscosity values remains unresolved [15].

In addition, the studied hydration processes $[16,17]$ prove that the mechanism of action of cellulose esters is not limited to water retention, but also leads to a slowdown in the hydration activity of cements and slow down the formation of CSH gel. The authors of [18] considered the effect of sulfate compounds in the hydration of clinker for 28 days. The data obtained allow to conclude that the presence of sulfate ion adversely affects the set of strength. The decrease in the strength of the samples occurred linearly for 28 days.

Among the main areas of problem solving, the authors of studies [19, 20] considered the use of only one concentration of additives in determining its effect on physicomechanical and rheological characteristics. However, in [17], where the study of the effect of cellulose esters is aimed mainly at studying the effect of different types of cellulose esters, as in previous works, the effect of changes in concentration was not considered. And none of the works raised the question of the resistance of such mixtures to the effects of aggressive environments.

The considered work [18], which is based on the study of changes in the component composition of the cement mixture, generally confirms the invariable data of existing studies [21,22] on the influence of aggressive environments. However, due to the authors' tests in only one environment, the work [18] is not indicative enough to study the solution.

Existing studies [23] address the lack of test environments. However, in their work, the authors did not take into account the modified mixtures, which in general do not solve the problem of stability of mixtures using ordinary cements and soluble additives on the example of cellulose esters.

Thus, the question of studying the nature of the influence of the concentration of additives and their properties on the strength characteristics of cement-based products, in the case of periodic exposure to aggressive environments after 28 days of hardening of cement stone, is appropriate.

\section{Methods of research}

When carrying out these studies, the following indicators of cement with additives were determined: normal density, setting time, water separation of the cement mixture, water absorption of cement stone and strength at the age of 2, 7 and 28 days.

Normal density and setting time were determined according to the standard method on a Vicat apparatus in a test of normal consistency. Indicators of water separation and water absorption, respectively, were determined by the methods given in GOST B.2.7-239:2010 (EN 1015-11:1999, NEQ) «Building solutions. Test methods». Due to the fact that the study selected three reference points of concentration, these dependences of the normal density on the concen- 
tration were processed by the method of logarithmic approximation.

Compressive strength indices were determined by the method given in DSTU EN 196-1:2007 (EN 196-1:2005, IDT) «Methods for testing cement. Part 1. Determination of strength». During the research let's use Portland cement PC 400r-N. Methylhydroxyethyl cellulose of average 17000$23000 \mathrm{mPa} \cdot \mathrm{s}$ (CM) and high 20000-30000 mPa.s (BM) viscosity was selected as additives These components were introduced into dry building mixtures in an amount of 0.25-0.75 wt. \% (CM I, II, III and BM I, II, III, respectively). To determine the destructive effect of the sulfate environment, the samples were tested in solutions of sodium sulfates (3.0 wt. \%), magnesium (0.3 wt. \%) and calcium (0.2 wt. \%).

\section{Research results}

6.1. The influence of the viscosity of methylhydroxyethylcellulose on the rheological and physical properties of mixtures. It was found that the selected additives of methyl hydroxyethyl cellulose have different effects on the normal density, the setting time of the cement, water separation of the cement slurry and water absorption. The given test results in Table 1 unambiguously indicate that with an increase in the content of each type of additives, the normal density also increases.

Table 1

Normal density of mixtures and setting times

\begin{tabular}{|c|c|c|c|c|c|c|}
\hline \multirow{2}{*}{$\begin{array}{l}\text { Mix- } \\
\text { tuге }\end{array}$} & \multirow{2}{*}{$\begin{array}{c}\text { Additive } \\
\text { content, } \\
\text { wt. \% }\end{array}$} & \multirow{2}{*}{$\begin{array}{l}\text { Normal } \\
\text { den- } \\
\text { sity, \% }\end{array}$} & \multicolumn{2}{|c|}{ Setting time, g-min } & \multirow{2}{*}{$\begin{array}{l}\text { Water } \\
\text { separa- } \\
\text { tion, \% }\end{array}$} & \multirow{2}{*}{$\begin{array}{l}\text { Water } \\
\text { absorp- } \\
\text { tion, \% }\end{array}$} \\
\hline & & & Begin & End & & \\
\hline PC & 0 & 33.3 & $0-54$ & $1-30$ & 6.0 & 6.65 \\
\hline CM I & 0.25 & 35.1 & $1-57$ & $1-18$ & 3.5 & 4.75 \\
\hline CM II & 0.5 & 37.2 & $2-18$ & $1-30$ & 3.6 & 6.80 \\
\hline CM III & 0.75 & 38.9 & $2-35$ & $2-23$ & 6.1 & 8.02 \\
\hline BM I & 0.25 & 40.4 & $1-52$ & $1-20$ & 3.0 & 7.85 \\
\hline BM II & 0.5 & 42.8 & $2-35$ & $1-45$ & 3.0 & 8.80 \\
\hline BM III & 0.75 & 47.1 & 3-05 & $2-25$ & 8.7 & 12.30 \\
\hline
\end{tabular}

Note: РГ - 0 \% (рuгe cement); CM I - 0.25 wt \%, CM II 0.5 wt. \%, CM III - 0.75 wt. \% (cement with the addition of medium viscosity cellulose ethers); BM I - 0.25 wt. \%, BM II - 0.5 wt. \%, BM III $0.75 \%$ (cement with the addition of high viscosity cellulose ethers)

The results obtained allow to assert that with an increase in the concentration of the additive, a logarithmic character is noted (Fig. 1). An increase in normal density allows to conclude that a further increase in the concentration of the additive can lead to a concentration maximum. This will negatively affect the water-holding capacity of the mixture, since excess water will lead to phase separation, in turn, negatively affect the process of hydration of clinker minerals and curing in general.

The results are shown in Table 1 show that at a concentration of additives of 0.75 wt. \% (CM III and BM III) there is already a significant loss of water-conditioning capacity of the mixtures in comparison with the control. This indicates that when mixed with water, cellulose ethers in a given amount bind with water, forming coagulation structures. Such formations envelop the cement particles and do not allow the water to be evenly distributed to hydrate the cement and, thereby, slow down the onset of setting and increase water separation.

Normal

density, \%

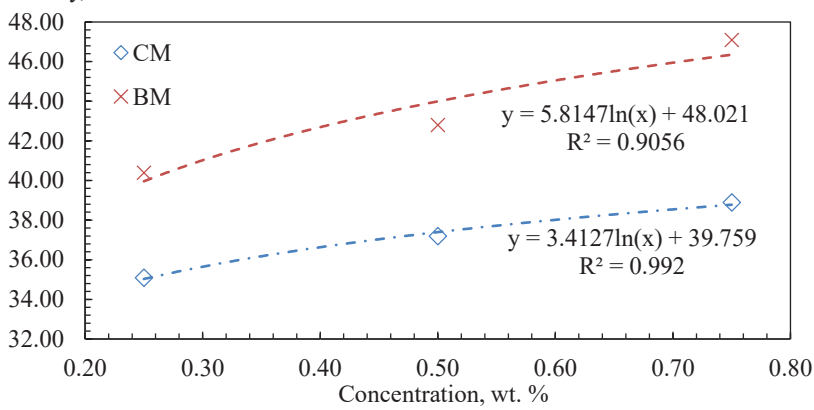

Fig. 1. Influence of the concentration of additives methyl hydroxyethyl cellulose of medium (CM) and high (BM) viscosity on the normal density of the solution

An increase in the concentration of additives, respectively, affects the structural characteristics of the hardened mixture, as evidenced by the results of determining the water absorption. In Fig. 2, it can be seen that cellulose ethers of high viscosity (BM) have a more radical effect on the water absorption rate in contrast to ethers of medium viscosity $(\mathrm{CM})$, the value of which for all three concentrations is within acceptable limits in accordance with the control samples.

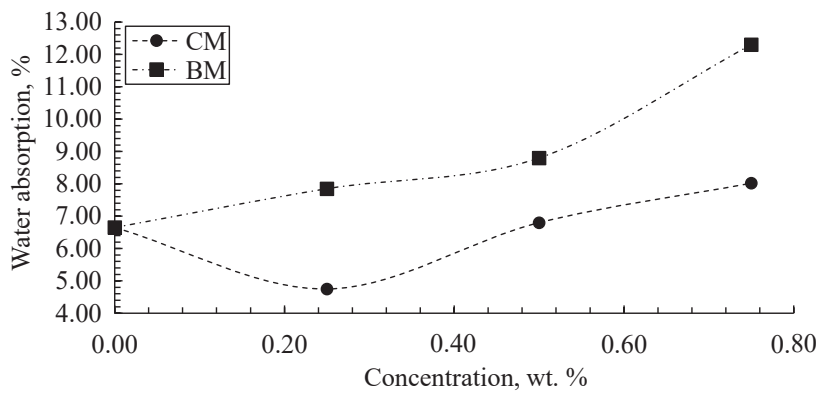

Fig. 2. Influence of cellulose ethers of medium (CM) and high (BM) viscosity on the water-clay ability of solidified samples

Thus, it can be argued that when using additives of cellulose ethers, a vitrification process occurs, which leads to the formation of a porous structure in the hardened stone. At the same time, in samples with high viscosity cellulose ethers (BM), this pore formation process is more intense, which can be seen at an additive concentration of 0.75 wt. $\%$.

6.2. The effect of methyl hydroxyethyl cellulose viscosity on the strength of the cement matrix. Taking into account the air-entraining ability of cellulose ethers, the addition of an additive will significantly affect the strength development.

With the introduction of medium viscosity cellulose ether additives, a significant drop in the early strength of the samples occurs (Fig. 3). This drop in strength, as already noted, is associated with the air-entraining ability of the additives. Concentrations of additives 0.25 and 0.50 wt. \% (CM I and CM II) during the hardening period have a linear growth in strength, which on the 28th day has almost leveled off, in contrast to the concentration of 0.75 wt. \% (CM III). 


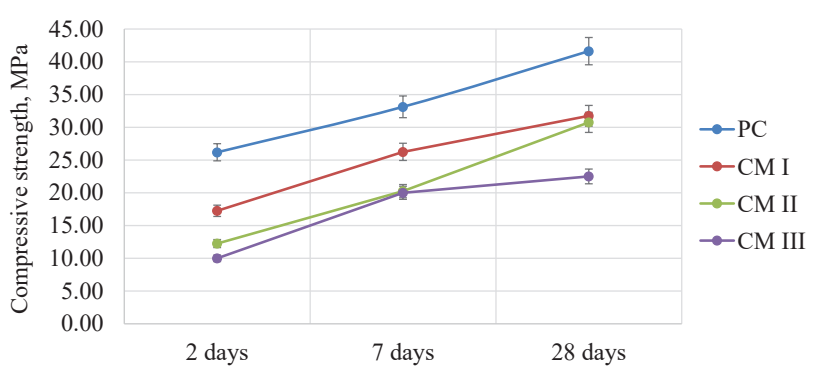

Fig. 3. Comparison of the strength gain of samples with the addition of methyl hydroxyethyl cellulose of medium viscosity of various concentrations

Such a difference in the nature of the growth of strength indicates that during the mixing process with water, not all cement particles are completely hydrated. Thus, in the thickness of the sample, both time and particulars of cement were present, which did not fully react due to the fact that they were isolated in the thickness of coagulation formations of cellulose ethers. Which, in turn, slowed down the formation of CSH gel and the binding of crystals of hydrated neoplasms of cement particles to each other.

The results obtained with the introduction of high viscosity cellulose ethers (BM) into cement differ from those of medium viscosity (CM) in that there is a significant decrease in strength over the entire concentration range (Fig. 4).

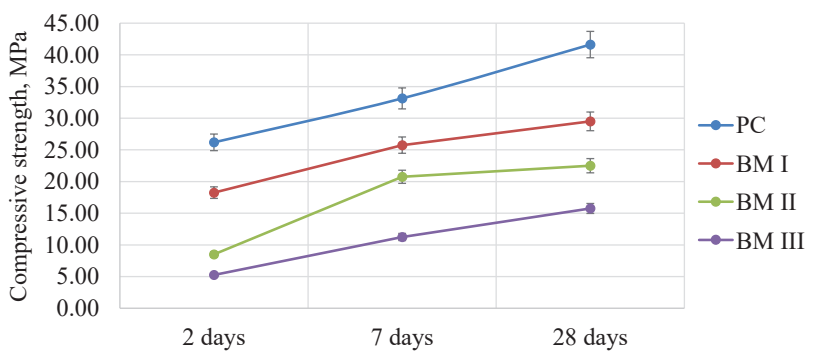

Fig. 4. Comparison of the strength gain of samples with the addition of high viscosity methyl hydroxyethyl cellulose of various concentrations

An increase in the additive content leads to a significant decrease in strength. With the general trend of a slow set of strength in the early stages of hardening, low strength indicators are also noted at the age of 28 days. The strength value for 28 days for each concentration will be, respectively, 29.1, 24.9 and $16.3 \mathrm{MPa}$.

6.3. Influence of sulfate medium on the strength of cements with methyl hydroxyethyl cellulose additives. One of the main agents of negative influence on the strength characteristics of cement products is mainly the environment containing compounds with sulfate ions. Since sulfate compounds are found both in ground and waste waters and in sea water, their presence is possible in humid environments of industrial zones. Thus, sulfate ions are absent in a free state in the medium, but in those combined with other cations, such as potassium, magnesium, sodium, calcium, etc. It is through this diversity that various media containing sulfate ions have a different effect on the strength of the samples. Therefore, changes in strength indicators under the influence of aggressive media are of great importance.
When studying the effect of the sulfate medium on the strength characteristics of cements with the addition of medium viscosity cellulose ethers (Fig. 5), it can be noted that the presence of various cations has a different effect on the strength of the samples, despite the fact that all have sulfate ions. It should be noted that when the strength of the samples in aggressive environments is clearly reduced after 168 days, the nature of the change in strength in the control samples made of pure cement for the CM samples is almost symmetric not only in terms of the type of environment, but also in the nature of the loss of strength.

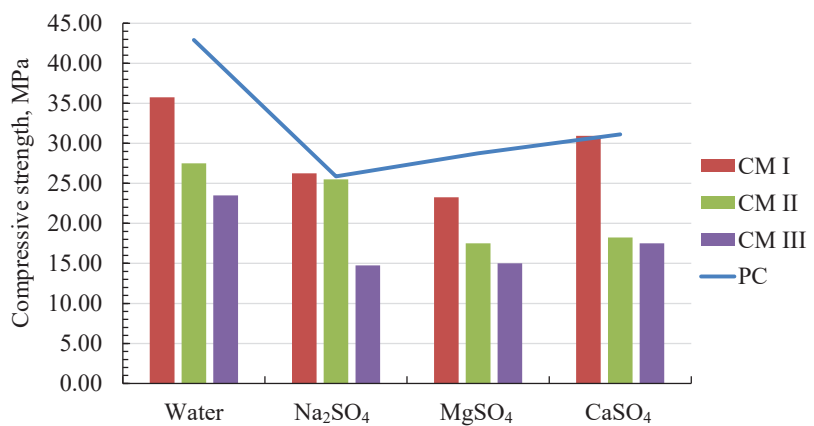

Fig. 5. Comparative characteristics of the strength of samples of medium viscosity in different environments for 168 days of aging

For samples containing high viscosity cellulose ethers (BM), the change in strength is more uniform and linear (Fig. 6).

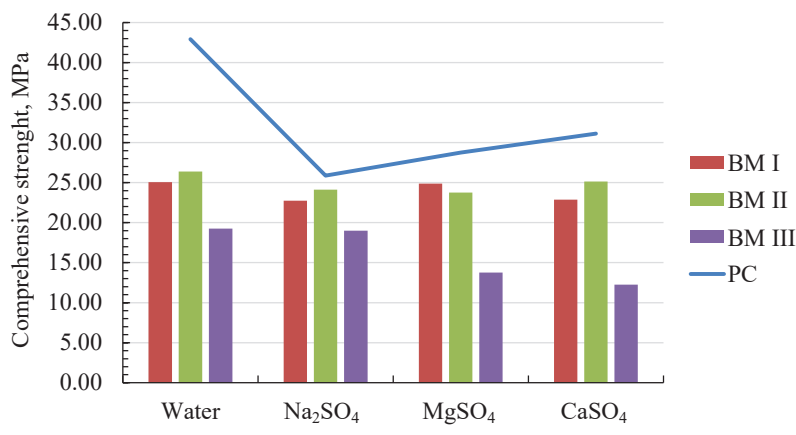

Fig. 6. Comparative characteristics of the strength of samples of high viscosity in various media on the 168th day of aging

It should be noted that for both types of cellulose ether at a concentration of $0.75 \mathrm{wt} \%$ There is a sharp drop in strength: for CM III, these are solutions of sodium and magnesium sulfate, for BM III, solutions of magnesium and calcium sulfate.

6.4. Discussion of the results of the effect of the sulfate ionic medium on the properties of cement slurries modified with cellulose ethers. The ability of methyl hydroxyethyl cellulose to retain water is confirmed by low water separation rates for concentrations of $0.25-0.75 \mathrm{wt}$. \%. In contrast to a mixture with high viscosity cellulose ether, at a concentration of 0.75 wt. \%, water loss begins to rise. This growth indicates that for this type of cellulose ethers, a high content negatively affects not only the water-holding capacity of solutions, but also during strength gain, as evidenced by its low indicators $(15.8 \mathrm{MPa})$ on the 28 th day of hardening. It should be noted that high viscosity 
cellulose ether retains more water than medium viscosity at 0.25 wt. $\%$ and 0.50 wt. $\%$ on $0.5-0.6 \%$ (Table 1 ). This also explains the significant increase in the setting time.

However, at 0.75 wt. \% water loss for the high viscosity cellulose ethers is $8.7 \%$, compared to the control $6.0 \%$. This value indicates that some of the water does not partially react with clinker minerals, and slows down the process of hydration and early strength.

Such changes in the course of hydration processes can't but affect the strength characteristics.

When it comes to the effect of the cellulose ether content on the strength of the cement stone, it must be remembered that the strength of pure cement is higher than its strength with additives, regardless of the concentration of the latter. In addition, the greatest decrease in the strength index is observed in the early periods of hardening (1-7 days) and is, depending on the concentration of the additive, respectively, by $2.2-4.2$ times. In the period of 7-28 days, this difference begins to decrease for samples with medium viscosity ethers, but not for high viscosity ethers (Fig. 3, 4).

Comparing the strength of cements with the same additive content among themselves, it is possible to conclude that the process of strength gain is the same for concentrations of $0.25-0.75$ wt. \% and has a linear character (Fig. 3, 4).

The introduction of methyl hydroxyethyl cellulose into cement also affects the corrosion resistance of cement (Fig. 5, 6).

Selected corrosive solutions are selected in accordance with the compounds that are more common in the operating environments of cement products. Thus, the investigated influence of the medium on the strength parameters shows in more detail the aspects of the process of destruction of samples by various mechanisms in the presence of other ions in a sulfate medium.

Based on the presence of active sulfate ions in solutions, it can be argued that destruction occurs due to the formation of calcium hydrosulfoaluminate in the microvoids of the samples. These formations lead to the further occurrence of mechanical stresses in the stone and, as a consequence, a gradual weakening of the strength characteristics for samples with medium viscosity cellulose ethers.

A somewhat different process occurs for samples containing high viscosity cellulose ethers in solutions of magnesium sulfate and calcium sulfate. First, there is the possibility that a certain amount of free magnesium oxide is present in the cement, which, when interacting with water, leads to the formation of magnesium hydroxide, which has no mechanical strength. Secondly, due to the possibility of the formation of coagulation structures of the ether, it is possible to form calcium hydrosulfoaluminate with the original clinker minerals, which were released after the dissolution of the cellulose ether particles.

If to compare the possible reactions, then the most aggressive is sodium sulfate solution. This is the case for the example of the control cement, the strength of which is the smallest in comparison with other solutions and is 25.9 MPa (Fig. 5, 6).

Quite different results with the introduction of cellulose ethers. So, the introduction of 0.25 wt. \% slows down the destructive nature of the sulfate environment by 1.5 times for all sulfate environments. And even the introduction of $0.50 \mathrm{wt}$ \% additive allows, in the case of the introduction of cellulose ethers of high viscosity, to improve the resistance to the destructive effect of magnesium sulfate solution, in comparison with the difference in the strength of cement without additives. A further increase in the content of additives in cements is not desirable, as it leads to a sharp drop in strength (Fig. 5, 6).

Thus, at low concentrations of methyl hydroxyethyl cellulose, some improvement in the corrosion resistance of materials is noted, and at significant concentrations, a sharp deterioration. This is due to both changes in the nature of the hydration processes of clinker, and a decrease in strength indicators with an increase in the content of cellulose ether in the material and its increased porosity.

The results obtained show that the use of cellulose ethers additives is expedient for slowing down the destruction processes under the influence of sulfate media, but at the same time loss of strength, in comparison with cements without additives, is inevitable.

Thus, it can be argued that the viscosity of cellulose ethers affects not only the ability to retain water in solutions, but also affects the strength of the matrix and its resistance to corrosion.

\section{SWOT analysis of research results}

Strengths. The introduction of cellulose ether into cement improves its adhesive properties and reduces water separation, which increases the time of working with the building mixture (setting time). At low concentrations of the additive, the ability of mixtures to withstand the destructive effects of an aggressive sulfate-ionic environment also increases. There is the possibility of modeling formulations for the use of mixtures in different environments with the possible contact of different sulfate ionic environments.

Weaknesses. When studying cements with additions of cellulose ethers, their effect on hydration processes was mainly considered [14, 16, 20], while the viscosity factor of cellulose ethers has not yet been studied and was not taken into account when studying the effect of sulfate media on building mixtures.

Opportunities. Further research should be focused on studying the influence of other components of dry building mixtures on the strength integrity of products, taking into account the influence of aggressive environments. These are, first of all, redispersible powders, as well as the complex effect of all the main components of dry building mixtures on the physical and mechanical properties of the cement matrix. It is also worth taking into account the tests for the effect of corrosive environments and with the content of chloride ions.

The results obtained can be used in the production of dry building mixtures, and not only to optimize compositions and predict stability in various aggressive environments.

Threats. The costs of the enterprise when using the additive are the installed equipment for storing and dosing the cellulose ether itself, as well as its cost.

The negative aspects of the use of these additives are their effect on the set of strength of building mixtures. When esters are added, morning and final strength values are reduced compared to mixtures where pure cement was used. This loss in the early stages is half that of the control samples.

The additive is not universal for its use in all sulfate ionic media at a certain single concentration, due to the 
different effect of accompanying cation ions on cellulose ethers. For example: at high concentrations (0.75 wt. \%) esters of medium viscosity, it is possible to use them in magnesium and calcium sulfate media, where the destructive effect is less than in sodium sulfate media. At the same time, at the same concentration ( 0.75 wt. \%), cellulose ethers of high viscosity are more stable in sodium sulfate environment. The additive itself is difficult to use, therefore, one of the main negative effects on its effectiveness is deviation in formulations in production, which can be caused by a human factor.

\section{Conclusions}

1. The introduction of cellulose ether in cement affects the indicators of normal dough density and hardening time of solutions, and leads to an increase in these indicators. Increasing the concentration of esters of medium and high viscosity leads to a decrease in the water separation of the solution at concentrations of $0.25-0.50 \mathrm{wt}$. \%, for a concentration of 0.75 wt. \% there is an increase in water separation by $0.1-2.7 \%$, respectively. At a concentration of $0.50-0.75$ wt. \% there is an increase in water absorption from 6.80 to $12.30 \%$, which confirms the air entrainment of additives.

2. Cellulose esters have a negative effect on the set of early strength due to increased hardening time, which can be seen from the results on days 2 and 7 and is, compared to control samples, 2-3 times less depending on the amount of additive. The loss of strength for 28 days compared to control samples is on average for samples with esters of medium viscosity $27.8 \%$; for high viscosity esters - $44.9 \%$.

3. The presence of cellulose esters in general has a positive effect on resistance to sulfate media. With small amounts of additives, there is a significant reduction in the rate of destruction of the samples after contact with the aggressive environment in contrast to the control samples. This change is noticeable when comparing the loss of strength between design and control samples in aggressive environments. For sodium sulfate, the loss of strength is:

- in cellulose esters of medium viscosity for samples with concentrations of 0.25 wt. $\%-12.5 \%, 0.5$ wt. $\%$ $5.6 \%, 0.75$ wt. \% - $33.7 \%$;

- in high viscosity cellulose esters -0.25 wt. $\%-22.9 \%$. For magnesium sulfate, the loss of strength is:

- in cellulose esters of medium viscosity for samples with concentrations of 0.25 wt. $\%-15.7 \%, 0.5$ wt. \% $35.2 \%, 0.75$ wt. $\%-32.6 \%$;

- for samples with high viscosity cellulose esters at additive concentrations of 0.25 wt. $\%-15.7 \%$ and 0.75 wt. $\%-12.7 \%$.

For sulfate calcium medium, the loss of strength is:

- in cellulose esters of medium viscosity for samples with concentrations of 0.5 wt. \% - 32.4 \%, 0.75 wt. \% $21.3 \%$;

- for samples with high viscosity cellulose esters at additive concentrations of 0.25 wt. $\%-22.5 \%$, and 0.75 wt. $\%-22.2 \%$

Loss of strength for control cement: sodium sulfate $35.3 \%$, magnesium sulfate $-28.1 \%$, calcium sulfate $-22.2 \%$. At the same time, for some concentrations there was an increase in strength, which in turn allows to conclude that in some samples there are particles of starting clinker materials, which were activated only after interaction with solutions of aggressive media.

\section{References}

1. Rynok sukhykh budivelnykh sumishei: stan ta prohnozy (infohrafika) (2019). Budivelnyi portal No. 1. Available at: http:// budport.com.ua/news/13193-rinok-suhih-budivelnih-sumisheystan-ta-prognozi-infografika

2. Dry Mix Mortar Market Share 2020-2026 (2019). Industry Statistics PDF Report. Available at: https://www.gminsights. com/industry-analysis/dry-mix-mortar-market

3. Wan, I. R. (2002). Advanced Dry Mortar Technology for Construction Industry. Professional Services Development Assistance Scheme, 1-19.

4. Rasheeduzzafar, Al-Amoudi, O. S. B., Abduljauwad, S. N., Maslehuddin, M. (1994). Magnesium-Sodium Sulfate Attack in Plain and Blended Cements. Journal of Materials in Civil Engineering, 6 (2), 201-222. doi: http://doi.org/10.1061/ (asce)0899-1561(1994)6:2(201)

5. Al-Amoudi, O. S. B., Maslehuddin, M., Saadi, M. M. (1955) Effect of magnesium sulfate sodium on the durability performance of plain and blended cements. ACI Materials Journal, 92 (1), 15-24. doi: http://doi.org/10.14359/1173

6. Al-Amoudi, O. S. B. (1995). Performance of 15 reinforced concrete mixtures in magnesium-sodium sulphate environments. Construction and Building Materials, 9 (3), 149-158. doi: http:// doi.org/10.1016/0950-0618(95)00007-3

7. Al-Amoudi, O. S. B. (1998). Sulfate attack and reinforcement corrosion in plain and blended cements exposed to sulfate environments. Building and Environment, 33 (1), 53-61. doi: http://doi.org/10.1016/s0360-1323(97)00022-x

8. Behr, M., Rosentritt, M., Loher, H., Kolbeck, C., Trempler, C., Stemplinger, B. et. al. (2008). Changes of cement properties caused by mixing errors: The therapeutic range of different cement types. Dental Materials, 24 (9), 1187-1193. doi: http:// doi.org/10.1016/j.dental.2008.01.013

9. Libos, I. L. S., Cui, L. (2020). Effects of curing time, cement content, and saturation state on mode-I fracture toughness of cemented paste backfill. Engineering Fracture Mechanics, 235, 107174. doi: http://doi.org/10.1016/j.engfracmech.2020.107174

10. Soja, W., Georget, F., Maraghechi, H., Scrivener, K. (2020) Evolution of microstructural changes in cement paste during environmental drying. Cement and Concrete Research, 134 106093. doi: http://doi.org/10.1016/j.cemconres.2020.106093

11. Balčiūnas, G., Pundienè, I., Boris, R., Kairytė, A., Žvironaitè, J. Gargasas, J. (2018). Long-term curing impact on properties, mineral composition and microstructure of hemp shive-cement composite. Construction and Building Materials, 188, 326-336. doi: http://doi.org/10.1016/j.conbuildmat.2018.08.126

12. John, V. M., Quattrone, M., Abrão, P. C. R. A., Cardoso, F. A (2019). Rethinking cement standards: Opportunities for a better future. Cement and Concrete Research, 124, 105832. doi: http:// doi.org/10.1016/j.cemconres.2019.105832

13. Kovalenko, Y., Tokarchuk, V., Poliuha, V. (2020). The effect of methyl hydroxyethyl cellulose on the cement matrix properties. Eastern-European Journal of Enterprise Technologies, 3 (6 (105)), 28-33. doi: http://doi.org/10.15587/1729-4061.2020.205347

14. Omikrine Metalssi, O., Aït-Mokhtar, A., Ruot, B. (2014). Influence of cellulose ether on hydration and carbonation kinetics of mortars. Cement and Concrete Composites, 49, 20-25. doi: http:// doi.org/10.1016/j.cemconcomp.2014.01.011

15. Spychał, E. (2015). The Effect of Lime and Cellulose Ether on Selected Properties of Plastering Mortar. Procedia Engineering, 108, 324-331. doi: http://doi.org/10.1016/j.proeng.2015.06.154

16. Zhang, G., He, R., Zhao, G., Wang, Y., Wang, P. (2017). Effect of Hydroxyethyl Methyl Cellulose on the Morphology Characteristics of $\mathrm{Ca}(\mathrm{OH}) 2$ in Portland Cement Paste. Jianzhu Cailiao Xuebao. Journal of Building Materials, 20 (4), 495-500.

17. Ou, Z. H., Ma, B. G., Jian, S. W. (2012). Influence of cellulose ethers molecular parameters on hydration kinetics of Portland cement at early ages. Construction and Building Materials, 33 78-83. doi: http://doi.org/10.1016/j.conbuildmat.2012.01.007

18. Ma, Y., Oian, J. (2018). Influence of alkali sulfates in clinker on the hydration and hardening of Portland cement. Construction and Building Materials, 180, 351-363. doi: http://doi.org/ 10.1016/j.conbuildmat.2018.05.196 
19. Zhang, G., Wang, P. (2014). Study of hydration process of cement paste modified with hydroxyethyl methyl cellulose by AC impedance spectroscopy. Jianzhu Cailiao Xuebao/Journal of Building Materials, 17 (1), 9-14. doi: http://doi.org/10.3969/ j.issn.1007-9629.2014.01.002

20. Wang, Z., Zhao, Y., Zhou, L., Xu, L., Diao, G., Liu, G. (2019) Effects of hydroxyethyl methyl cellulose ether on the hydration and compressive strength of calcium aluminate cement. Journal of Thermal Analysis and Calorimetry, 140 (2), 545-553. doi: http://doi.org/10.1007/s10973-019-08820-6

21. Ou, Z. H., Ma, B. G., Jian, S. W. (2013). Pore Structure of Cement Pastes Modified by Non-ionic Cellulose Ethers. Journal of Building Materials, 16 (1), 121-126. doi: http:// doi.org/10.3969/j.issn.1007-9629.2013.01.023

22. Djuric, M., Ranogajec, J., Omorjan, R., Miletic, S. (1996). Sulfate corrosion of portland cement-pure and blended with $30 \%$ of fly ash. Cement and Concrete Research, 26 (9), 1295-1300. doi: http://doi.org/10.1016/0008-8846(96)00127-5

23. Bérodier, E. M. J., Muller, A. C. A., Scrivener, K. L. (2020). Effect of sulfate on C-S-H at early age. Cement and Concrete Research, 138, 106248. doi: http://doi.org/10.1016/j.cemconres. 2020.106248
Kovalenko Yurii, Assistant, Department of Chemical Technology of Composite Materials, National Technical University of Ukraine «Igor Sikorsky Kyiv Polytechnic Institute», Kyiv, Ukraine, e-mail kovalenko91993@gmail.com, ORCID: http://orcid.org/0000-00030714-3816

Klymenko Anatoliy, PhD, Senior Researcher, Department No. 28 «Welding of Gas and Oil Pipelines», E. O. Paton Electric Welding Institute of the National Academy of Sciences of Ukraine, Kyiv, Ukraine, e-mail: Aklimenko@meta.ua, ORCID: http://orcid.org/ 0000-0001-9148-8221

Tokarchuk Vladimir, PhD, Associate Professor, Department of Chemical Technology of Composite Materials, National Technical University of Ukraine «Igor Sikorsky Kyiv Polytechnic Institute», Kyiv, Ukraine, e-mail: tokarchuk.volodya@ukr.net, ORCID: http://orcid.org/ 0000-0001-8620-954X

Sviderskyi Valentyn, Doctor of Technical Sciences, Professor, Department of Chemical Technology of Composite Materials, National Technical University of Ukraine «Igor Sikorsky Kyiv Polytechnic Institute», Kyiv, Ukraine, e-mail: xtkm@kpi.ua, ORCID: http:// orcid.org/0000-0002-5956-6987 